\title{
Fate of Manuscripts Rejected by Turkish Archives of Otorhinolaryngology between 2015 and 2017
}

\author{
Editorial $>\begin{aligned} & \text { Turgut Karlıdağ }{ }^{1} \text { (D), Cem Bilgen }{ }^{2} \text { (D), Taner Kemal Erda } \breve{g}^{3} \text { (D) } \\ & { }^{1} \text { Department of Otorhinolaryngology, Frrat University School of Medicine, Elazığ, Turkey }\end{aligned}$ \\ ${ }^{2}$ Department of Otorhinolaryngology, Ege University School of Medicine, İzmir, Turkey \\ ${ }^{3}$ Department of Otorhinolaryngology, Dokuz Eylül University School of Medicine, İzmir, Turkey
}

ORCID iDs of the authors: T.K. 0000-0003-2748-7309; C.B. $0000-0003-0853-1095$; T.K.E. 0000-0001-5636-3343.

Cite this article as: Karlıdağ K, Bilgen C, Erdağ TK. Fate of Manuscripts Rejected by Turkish Archives of Otorhinolaryngology between 2015 and 2017. Turk Arch Otorhinolaryngol 2020; 58(2): 78-9.

\section{Corresponding Author:} Turgut Karlıdağ, turgut_karlidag@yahoo.com

Content of this journal is licensed under a Creative Commons Attribution 4.0 International License. Available online at www.turkarchotolaryngol.net

\section{(c) (i) \$}

DOI: $10.5152 / \operatorname{ta0} .2020 .0332$
In the process of accepting submitted manuscripts for publication, originality of the study, clinical significance and usability of the study results, methodologic quality, and whether or not the content would spark interest among the journal's readership are the major criteria (1). Selecting manuscripts for the journal, therefore, involves a challenging and complex process. Evaluation of the manuscripts by the editorial board and the peer reviewers constitute an important stage in the process and only a small portion of the submitted manuscripts are eventually accepted for publication (1-6).

Investigating the outcome of rejected manuscripts bears importance for several reasons. These include, providing feedback to the authors about the evaluation process and the aspects they should reconsider when submitting their manuscript to other journals. It will also allow the authors to get an idea of the reasons why, if any, their manuscripts are delayed for publication, as well as the quality of the journal in which they anticipate to have presence $(2,7)$.

The aim of this study is to investigate the outcomes of the manuscripts that were submitted to and rejected by the Turkish Archives of Otorhinolaryngology (TAO) in the period from January 2015 to December 2016.

Manuscripts rejected by TAO in the period from January $1^{\text {st }}, 2015$ to December $31^{\text {st }}, 2016$ were included in the study. The data was analyzed by the number of manuscripts submitted to TAO in the indicated period; the number of rejected manuscripts and their types (experimental study, clinical study, case report, review, letter to editor); the number of manuscripts that were accepted by another journal after being rejected by TAO; the review stage at which the manuscripts were rejected (whether at review by editor or by peer reviewers); mean time to rejection (mean time from receipt of the manuscript by the editor until the decision to reject).

Additionally, types of the manuscripts that were accepted by another journal after being rejected by TAO; title of the publishing journal; the time to their acceptance or publication by another journal after rejection; whether the manuscript was published in a different language (Turkish/English); whether there were any changes to the number of authors or the order of names, and the content (whether or not the manuscript was revised in regard of the reviewers' comments provided by TAO) were analyzed. The status of the database in which the publishing journal is indexed was compared for superiority/inferiority to that of TAO. As the TAO and some of the other journals that published papers rejected by TAO have not been included in Science Citation Index Expanded (SCIE), these journals do not have formal impact factor values. As the comparison could not be made in terms of impact factors of the journals, TAO and other journals which published articles rejected by TAO were categorized according to their main indexes. Accordingly, group A composed of journals indexed in SCIE with or without inclusion in PubMed and/or Scopus, group $\mathrm{B}$ composed of journals indexed in PubMed and/or Scopus and journals indexed in other international and/or national indexes comprised group $\mathrm{C}$. 
Search was conducted on Google Scholar, PubMed, and the one national databases named ULAKBİM TR Index for the rejected manuscripts included in the study. The search was conducted separately on these databases not only by title in Turkish and English, but also the names of the first two and the last authors.

In the indicated period, a total of 159 manuscripts were submitted to TAO, of which $90(56.6 \%)$ were rejected. While the mean time to rejection was 25.5 days (range: 1 to 134 days), 49 (54.4\%) were rejected after peer review and 41 (45.6\%) were rejected during editorial review. Of the rejected manuscripts, 43 (47.7\%) were case reports, 39 (43\%) were clinical studies, 7 (8\%) were reviews, and $1(1 \%)$ was a letter to the editor.

Sixty-eight (75.5\%) of the manuscripts rejected by TAO were identified to have been published in other journals within a mean of 210 days (range: 20 to 726 days). Of these 68 manuscripts, change of language was identified in $4(5.8 \%)$, change in number of authors in 16 (23.5\%) (fewer in nine and more in seven), change in order of author names in 18 (26.4\%), and content was identified to have been revised in $30(44.1 \%)$ after rejection in regard of the reviewers' comments.

Of the manuscripts rejected by TAO, nine (10\%) were published in group A journals (Table 1), and content was identified to be revised in all except one; 59 (65.5\%) of the rejected manuscripts were published in group C journals and 19 (21.1\%) manuscripts were not published in any journal. Also three (4.6\%) were identified to be published in predatory journals. Of the manuscripts rejected by TAO and published in group $\mathrm{C}$ journals, 25 were published in local Turkish otorhinolaryngology (ORL) journals and six were in local Turkish general medicine journals.

Many editors inevitably reject manuscripts because they receive more submissions than they can publish. The reasons for the rejection of a manuscript does not constitute an obstacle for its publication in another journal (1-4). A study which investigated the outcomes of 350 manuscripts rejected by Annals of Internal Medicine reports that $69 \%$ of these manuscripts were published in a journal with a lower impact factor within a mean of 18 months (8). Other studies on this topic report that 40 to $75 \%$ of the rejected manuscripts were published in another journal, and of

Table 1. Group A journals which published the manuscripts rejected by Turkish Archives of Otorhinolaryngology

\begin{tabular}{l|c}
\hline Journal name & No. of manuscript \\
\hline Journal of Craniofacial Surgery & 2 \\
\hline Journal of Voice & 1 \\
\hline American Journal of Otolaryngology & 1 \\
\hline The Journal of International Advanced Otology & 1 \\
\hline Canadian Journal of Diabetes & 1 \\
\hline Ear, Nose \& Throat Journal & 1 \\
\hline The Turkish Journal of Pediatrics & 1 \\
\hline Hippokratia & 1 \\
\hline
\end{tabular}

these 2.3 to $14 \%$ were published in a journal with a higher impact factor (1-9). Our study showed that $56.6 \%$ of the manuscripts submitted to TAO were rejected and $75.5 \%$ of the rejected manuscripts were published in another journal. Of these, $10 \%$ were published in a journal in a higher rank index than that of TAO.

The authors of a manuscript rejected in TAO should not be despairing and should look for other journals for their appropriately revised papers considering the reviewers' comments and recommendations. Because there is a high probability of being accepted for publication in some other journals.

The content change in $44.1 \%$ of articles published in other journals after being rejected in TAO is pleasing as it is an evidence that the evaluation process in TAO contributed to the revised papers. On the other hand, the fact that there were also changes in the number or order of the authors suggests that there might be some ethical problems in the published articles.

Other than to give information to the authors of rejected articles, this review also enabled the editorial board of TAO to see their performance in the evaluation of submitted articles. The fact that only $10 \%$ of the articles rejected in TAO have been published in higher quality journals indicates that editorial board of TAO is correct in identifying the appropriate articles for the journal.

The information gathered in this review might be useful not only for the readers who can be also potential authors but also for the editorial board of TAO. Similar periodical studies can also be performed to improve the quality of local otorhinolaryngology journals.

\section{References}

1. Wijnhoven BP1, Dejong CH. Fate of manuscripts declined by the British Journal of Surgery. Br J Surg 2010; 97: 450-4. [Crossref]

2. Earnshaw CH, Edwin C, Bhat J, Krishnan M, Mamais C, Somashekar $\mathrm{S}$, et al. An analysis of the fate of 917 manuscripts rejected from Clinical Otolaryngology. Clin Otolaryngol 2017; 42: 709-14. [Crossref]

3. Zoccali C, Amodeo D, Argiles A, Arici M, D'arrigo G, Evenepoel $\mathrm{P}$, et. al. The fate of triaged and rejected manuscripts. Nephrol Dial Transplant 2015; 30: 1947-50. [Crossref]

4. Grant WD, Cone DC. If at first you don't succeed: the fate of manuscripts rejected by Academic Emergency Medicine. Acad Emerg Med 2015; 22: 1213-7. [Crossref]

5. Okike K, Kocher MS, Nwachukwu BU, Mehlman CT, Heckman JD, Bhandari M. The fate of manuscripts rejected by The Journal of Bone and Joint Surgery (American Volume). J Bone Joint Surg Am 2012; 94: e130. [Crossref]

6. Dewan P, Gupta P, Shah D. Fate of articles rejected by Indian Pediatrics. Indian Pediatr 2010; 47: 1031-5. [Crossref]

7. Walker R, Rocha da Silva P. Emerging trends in peer review-a survey. Front Neurosci 2015; 9: 169. [Crossref]

8. Ray J, Berkwits M, Davidoff F. The fate of manuscripts rejected by a general medical journal. Am J Med 2000; 109: 131-5. [Crossref]

9. Lee KP, Boyd EA, Holroyd-Leduc JM, Bacchetti P, Bero LA. Predictors of publication: characteristics of submitted manuscripts associated with acceptance at major biomedical journals. Med J Aust 2006; 184: 621-6. [Crossref] 